\title{
The Twilight of the Scientific Age Martín López Corredoira
}

Brown Walker Press, Boca Ratón, Florida, 2013, 208 págs.

\author{
Jorge Gibert Galassi ${ }^{1}$ \\ Universidad de Valparaíso, Valparaíso, Chile. \\ Email: jorge.gibert@uv.cl
}

La similitud de las organizaciones científicas contemporáneas con las empresas transnacionales ha generado críticas. Pero pocas veces ellas vienen de un defensor y protagonista de la empresa científica. Es el caso de Martín López Corredoira y su más reciente libro, The Twilight of the Scientific Age.

El texto interconecta tres aspectos: filosofía, historia y sociología de la ciencia. La tesis central del libro, en términos gruesos, se resume en que la ciencia está desapareciendo debido a que: i) se ha convertido en una empresa de contabilidad de detalles (irrelevantes) de la realidad; ii) no ofrece un sentido a la vida de las personas; y, iii) el espíritu científico se ha corrompido debido a la institucionalización de la investigación científica profesional.

Su motus central es la reivindicación de la ciencia, aunque dentro de una perspectiva que no rechaza la posibilidad de su obsolescencia histórica. Los hechos son parte central del libro: una montaña de datos significativos, entre los que se cuenta el incremento exponencial de las actividades de investigación, que López sugiere no es sinónimo de ciencia. El libro defiende el principio metafísico que todo en el universo es un fenómeno natural que puede ser estudiado de un modo empírico-racional. Por cierto, cree que quedan misterios por resolver, pero nada puede ser dicho de modo confiable excepto a través de la ciencia. El autor quiere transmitir su amor por la ciencia, "una pasión por la lógica y por la comprensión de los mecanismos que gobiernan la naturaleza”.

Básicamente mediante la comparación de la gran ciencia de ayer versus la "investigación” ó pequeña ciencia de hoy, López da ejemplos históricos del "espíritu científico" caracterizado por la honestidad y la "caballerosidad” científica, como el caso de la teoría de la evolución de WallaceDarwin, que además nos muestra la importancia de un bagaje cultural amplio que permitió extrapolar una idea económica al campo de la biología. Precisamente lo que no ocurre hoy debido al enclaustramiento intelectual en los laboratorios especializados, que restringen la creatividad.

Pero su planteamiento no es una idealización del pasado, ya que el 
texto enumera prácticas que permanentemente han detenido el pensamiento científico, como la renuencia a creer en los hechos que señala la observación, a menos que exista una teoría que los explique. Pone en el banquete de los acusados también a la experimentación y los cálculos, desdeñada como “diversión para los técnicos"; y, el embelesamiento con las modas, como sucede hoy con la tecno-ciencia, considerada por López solo una manera de recaudar fondos para seguir coleccionado detalles descriptivos. Con esto último, desliza la idea que muchos científicos contemporáneos son como Barry Kripke, el personaje de TV (The Big Bang Theory). Kripkese define así: “(soy) un pragmático (de la teoría de cuerdas). Digo que voy a probar algo que no puede ser probado. Postulo a subsidios monetarios y luego me los gastó en licor y mujeres”.

El autor sugiere que la actual Big Science (un montón de dinero tirado como grasa a un engranaje institucional) sólo emula una época de oro, donde el genio individual y los presupuestos modestos eran la regla, como en el caso de Santiago Ramón y Cajal y muchos otros. Además, a través de sugerentes afirmaciones, explica que tal ciencia nunca fue relativista, no consistió en detalles, no fue ortodoxa ni tampoco muy amiga de los poderosos. La ciencia desde sus comienzos se opuso al dogmatismo y se desarrolló bajo el alero del espíritu crítico. Pero el nuevo dogmatismo consiste en que "la inteligencia y la creatividad son despreciadas en los lugares donde la tecnología y el dinero ocupan posiciones privilegiadas”. Ello le obliga a "alzar la voz para preservar los valores científicos, contra la corrupción y la decadencia, hoy en día generalizadas”.

El enemigo que ve López en la ciencia actual es que hay un valor económico asociado con el "valor” de la ciencia. Haciendo un cálculo, afirma que en las últimas décadas se ha gastado el 99\% del dinero en investigación y no se ha generado ninguna gran teoría; mientras que los grandes hitos de la historia de la ciencia pura son producto del 1\% de inversión, en toda la historia anterior de la humanidad. La tendencia es: crecen los gastos (en investigación) mientras que disminuyen los resultados científicos relevantes. López no confunde ciencia con datos o información. La profesionalización de la ciencia implica un número creciente de funcionarios, sin pasión por la ciencia, aunque sí con mucho amor al dinero. Pero el autor afirma que una idea científica no espera por financiamiento, debido a que la ciencia no es un producto industrial que espera la aprobación de una postulación burocrática. Citando una novela: "La disciplina es buena para la milicia; la tenacidad es buena para la religión; la pasión es lo único que mueve a la ciencia”. En el fondo, López es un romántico, pues cree necesario apelar al corazón, en momentos en que la ciencia está administrada para excluir a los apasionados. La institucionalización de la ciencia fortaleció la ortodoxia y dejo fuera las ideas originales, excomulgadas por la ciencia burocrática.

El autor afirma que la ciencia, al igual que otras instituciones de la historia, transitó desde una etapa novedosa, donde un puñado de hombres redefine las tendencias dominantes (etapa revolucionaria) a un perío- 
do intermedio, donde se evidencian los logros para la sociedad de la nueva forma social, llegando a una tercera, donde la sociedad crea canales de financiamiento para mantener la función así construida en torno a una burocracia (etapa institucional). La ciencia esta hoy en esta tercera etapa, maquinal y carente del espíritu que le dio origen. ¿Cuál es la motivación para hacer ciencia hoy? Se infiere del libro que es el dinero.

Dentro de las características de la dinámica actual, López menciona en primer lugar, el recurso humano ubicado en el comienzo de la pirámide jerárquica, los estudiantes de posgrado, los "esclavos"; y los becarios postdoctorales, "esclavos de verano". Normalmente sólo constituyen fuerza de trabajo de los investigadores permanentes, ocupados en cuestiones de laboratorio, carecen de guía intelectual y de tiempo para desarrollar sus propias ideas, cuestión sistémicamente censurada.

El funcionamiento de las revistas es otra faceta cuestionada por López. El sistema de revisión ciega (o doble-ciego) a veces, efectivamente, es no-vidente respecto de la valía de un trabajo. Por un lado, la rutinización de la actividad creadora se manifiesta en la producción de trabajos inscritos en las corrientes dominantes de pensamiento, constituyendo meros planteamientos de puzzle-solving. Las ideas realmente heterodoxas, aunque buenas, no tienen cabida en el mundo de los journals importantes. Citando a Madox, el autor repite que si Newton hubiera enviado su trabajo de teoría de la gravedad a una revista actual, hubiera sido rechazado como "un absurdo”. Así, se publica mucho, pero sólo detalles. Por otro lado, la conexión entre publicaciones en revistas prestigiosas y obtención de subsidios monetarios de investigación hace que los evaluadores muchas veces tengan conflictos de interés, debido a que se constituyen en jueces y partes del sistema de reconocimiento científico. "El control de la comunicación y la práctica del poder están estrechamente relacionadas”, dice López. Los científicos se autocensuran sus ideas novedosas para que el trabajo sea "aceptado”. Los revisores no detectan los errores y, al final, se acepta o rechaza el trabajo por consideraciones ajenas al mérito científico del mismo.

Yo diría que López va más allá de la afirmación que la reputación está concentrada y que manifiesta una ley de potencia: apostaría que desprecia la cienciometría, el índice $\mathbf{h}$ y todo lo demás, pues lo encuentra nocivo para que se desarrollen las nuevas ideas en las mentes de los científicos jóvenes, subyugados por "el juego de la ciencia”. Yo defendería la idea que López desliza: como está ampliamente demostrado que el proceso de revisión ciega tiene fallas, volvamos al sistema de pares reconocibles, que exista un diálogo entre autor y revisor, y que las revistas empiecen a publicar ideas extraordinarias y polémicas en vez de manchas de tinta de mainstream. Ni hablar de los congresos. Las conferencias Solvay ya no existen: sólo reuniones de propaganda y turismo científico.

Finalmente, la colaboración científica solo es otra expresión de una actividad de "big numbers" (número de personas, cantidades de dinero, etc.). La visión de la co-autoría de trabajos como virtud epistémica es reem- 
plazada por la “ciencia corporativa democrática-capitalista de consenso”. Esto significa que la fruta del árbol de la ciencia, que es el conocimiento, puede ser saboreada por cualquiera: es la tradición democrática de la ciencia. Para López, el individuo creador es reemplazado por una industria multinacional, una maquinaria, buscadora de ganancias o impactos, que ubica sólo en un segundo lugar la búsqueda del conocimiento. Por el contrario, la ciencia es una actividad aristocrática, donde los avances solo pueden ser advertidos por una elite intelectual minoritaria.

La elevación de Gregory Perelman al status de "héroe” sugiere que la renuncia es la redención para el genio científico, víctima de la farsa de sus comunidades académicas. El rechazo de sendos premios internacionales es una denuncia de las mafias del "MathStablishment”. Si eso pasa en matemáticas, cuyas formulaciones ideales son irrefutables, la situación no puede ser mejor en ninguna otra disciplina.

La ciencia es un tipo de empresa intelectual, que genera productos (ideas y métodos), bajo aleros institucionales distintivos. López es un hombre de ciencia y, a pesar de su romanticismo científico, acepta la idea que la importancia de la ciencia es histórica y que su cultivo no implica solución necesaria al misterio de la existencia humana. La tesis del autor tiene cierta ambivalencia: por un lado, históricamente, plantea el ocaso de la era científica, debido a que los grandes productos ya fueron elaborados; pero por otro, sociológico, afirma que si no fuera por la maquinaria de producción ortodoxa, la creatividad científica podría seguir desarrollándose y elaborando "grandes productos". Dicho de otra manera, debido a restricciones epistémicas objetivas, no se puede conocer más donde no existe nada más, esto es, las características relevantes de la naturaleza son conocidas, luego, estamos en una época de detalles que inevitablemente terminaran por aburrirnos. Pero por otro lado, López atribuye la escasez de nuevas ideas a una suerte de determinismo sociológico, esto es, la ciencia configurada como espacio social institucional impide el desarrollo de la creatividad y la heterodoxia individual: ¿cómo puede impedir tal desarrollo si objetivamente la naturaleza aún tiene "importantes” cosas que mostrarnos? Probablemente, el autor podría refutar esto con un argumento “gradualista”, y así tratar de evitar el dilema.

El libro es de una claridad maravillosa, contiene muchas verdades y no pocas tesis audaces pero plausibles, además, está extraordinariamente bien documentado. Todo intelectual con intereses en la filosofía, la historia o la sociología de la ciencia puede ser beneficiado con su lectura. 
Jorge Gibert Galassi

\section{Nota}

${ }^{1}$ El autor agradece el apoyo de CONICYT a través del proyecto FONDECYT 1130559. 